\title{
A message behind a smile: how facial expression supports communication in marketing
}

\author{
Andhy Setyawan, Dudi Anandya \& Farenza Renada Fulongga \\ University of Surabaya, Surabaya, Indonesia
}

\begin{abstract}
A smile is a form of facial expression which contains a message of a person's feelings that allows the transmission of emotion to others. In marketing communications, emotional contagion can be an individual evaluation of advertising, brands, and even purchase intentions. Using experimental techniques, this study aims to understand the impact of facial expression on consumer evaluation with emotional contagion mediation. Data from 120 participants involved in laboratory experiments were processed using ANOVA and Linear Regression. The result showed the presence of emotional contagion felt by the individual when observing the facial expression of endorser in an advertisement. Furthermore, this emotional contagion mediates the effect of facial expression on consumer evaluation. Consumer evaluation in this study refers to attitude towards advertising, brand, and intention of purchasing product.
\end{abstract}

Keywords: facial expression, emotional contagion, attitude, purchase intentions, marketing communications

\section{INTRODUCTION}

A person's facial expressions show internal emotions that are perceived and able to influence others around him. Other people may recognize the emotions that a person feels through facial expression. Doherty (1997) believes that emotions expressed through facial expressions are capable of affecting the emotions of others through emotional contagion.

The concept of facial expression and its influence on the marketing environment is widely applied to marketing communications. Marketing communications which show endorsers' facial expressions that match with the product being promoted is one of the important conditions in persuasion efforts (Choi \& Rifon 2012). The expression shown by endorsers in an advertisement has a major contribution affecting consumers to enhance their positive attitude and purchase intentions (Ilicic \& Webster 2011).

Although many previous studies have examined various approaches to enhance the endorsers' effectiveness of promotions, there were only a few types of research in the marketing field that examine the effect of facial expression on consumer evaluation of advertising, branding, and behavior. The purpose of this study focuses on the disclosure of the facial ex- pression role of the endorser (in the form of a smile or a flat expression) in influencing consumer emotion as well as its evaluation of advertising, brand, and purchase intentions.

\subsection{Facial Expression}

A smile is one of the facial expressions that can enhance a positive feeling within oneself as compared with a flat facial expression (Soussignan 2002). Previous studies show that the smile expression of an ad model will affect the emotional state of the consumer who sees the ad becoming more positive (Baxter et al. 2014, Davis \& Herr 2014). Recent research of Kulczynski et al. (2016) shows that smiley facial expression of an endorser in an advertisement causes consumers who see the ad to feel happier and respond positively. Thus, the first hypothesis is proposed as follows.

H1: Consumers will feel happier when seeing the smile expression of endorsers, regardless of the presence of certain cognitive messages.

\subsection{Emotional Contagion}

Emotional contagion is a reaction that emerges automatically as a result of one's observation of a cer- 
tain stimulus, such as various facial expressions (Winkielman et al. 2005). Some evidence suggests that a large number of consumer decisions are made automatically or unconsciously (Fitzsimons et al. 2002). Many researchers assume that the facial expressions of a source can alter the subconscious response of those who see it (Winkielman et al. 2005), so called an automated process.

Advertisements are designed in such a way as to convey emotions to consumers and encourage consumers to use their emotions in evaluating those advertisements. Referring to Yoo \& MacInnis (2005), the consumer's feelings arising from the advertisements shown can provide one of two kinds of influence: (1) consumer emotions cause them to give biased evaluations towards the advertisements; or (2) consumer feelings can also be mediated by thoughts related to the credibility of the advertisements.

The study results of Kulczynski et al. (2016) explain that the consumer's feeling of happiness generated by the smiley face expression of the endorser in advertisements can influence consumer evaluation. The referred consumer evaluation is a positive attitude towards advertising, brand, and purchase intentions. Referring to these discussions, the second hypothesis is proposed as follows.

H2a: Consumer's feeling of happiness will mediate the effect of a smile on attitude towards advertising.

$\mathrm{H} 2 \mathrm{~b}$ : Consumer's feeling of happiness will mediate the effect of a smile on attitude towards brand.

$\mathrm{H} 2 \mathrm{c}$ : Consumer's feeling of happiness will mediate the effect of a smile on attitude towards purchase intentions.

\section{RESEARCH METHODS}

The type of research conducted was causal research which is a research conducted to determine the causal relationship between the variables studied (Zikmund et al. 2013). ). The facial expression of the endorser on the ad was a manipulated variable as a cause and the emotion of the consumer who saw the ad as an effect that was going to be analyzed.

The data were collected using the laboratory experiment technique with students as theparticipant. The experimental design applied in this paper was a factorial design 2 (facial expression: smiling and resting) X 2 (cognitive capacity: load and no load). The study participants were divided into four groups of randomized treatment.

The research variables were operated by referring to Kulczynski et al. (2016). The facial expression variable was manipulated by exhibiting smiley face expression of endorsers in ads for smiling condition, and flat face expression for resting condition. Cognitive capacity was manipulated by creating load and no load conditions. The load condition was manipulated by giving participants the task to memorize a 7-digit random number before understanding the ad (Davis \& Herr 2014), while under no-load conditions the participant was asked to immediately understand the advertisement provided without any cognitive load.

Emotional contagion variables, attitude towards advertising, attitude towards the brand, and purchase intentions were obtained by measurement. Emotional contagion was operationalized with the SelfAssessment Manikin (SAM) referring to Bradley \& Lang (1994). SAM is a picture of one's emotions from sad to happy state. Furthermore, attitude towards advertising, attitude towards the brand, and purchase intentions were measured on a semantic differential scale, referring to Kulczynski et al. (2016).

Before testing the hypothesis, the validity and reliability of the collected data were first tested. For manipulated variables, manipulation checks needed to be done to determine the validity level of manipulation applied to participants (Zikmund et al. 2013). Manipulation checks were based on independent ttest results. The validity of variables was measured by correlation value of Pearson ( $\rho$ ) item to total (Sekaran \& Bougie 2016), while the reliability was tested using Cronbach's Alpha $(\alpha)$ is at least 0.7 (Hair et al. 2010).

Data analysis applied to test hypothesis 1 was an analysis of variance (ANOVA). Hypothesis 2 was tested by multiple linear regression analysis by applying mediation effects that refer to Baron \& Kenny (1986), and MacKinnon et al. (2002).

\section{RESULTS AND DISCUSSIONS}

The result of the manipulation checks indicates that the group of participants with the load cognitive capacity took significantly longer time to understand the ad $\left(\mathrm{M}_{\text {Load }}=11.1883\right.$ seconds $)$ than the no-load cognitive capacity $\left(\mathrm{M}_{N o \text { Load }}=8.1057\right.$ seconds, $t=$ 2.829, $p=0.005$ ), indicating that the manipulated cognitive capacity in participants works well.

Table 1 shows that all variable measurement indicators are valid because the Pearson correlation value was high and significant $(p \leq 0.01)$. Besides valid, measurements also showed good reliability because Cronbach's alpha value exceeds 0.7 . The validity and reliability testing of all variables, both manipulated and measured showed good validity and reliability so it was worth to proceed to the testing phase of the hypothesis. 
Table 1 . The validity and reliability testing on variables

\begin{tabular}{lcl}
\hline Variable & $\begin{array}{c}\text { Pearson } \\
\text { relation }\end{array}$ & Cronbach's alpha \\
\hline \multicolumn{2}{l}{ Attitude towards advertising } & \\
ATA1 & $0.908^{* *}$ & \\
ATA2 & $0.899^{* *}$ & 0.882 \\
ATA3 & $0.896^{* *}$ & \\
Attitude towards brand & & \\
ATB1 & $0.839^{* *}$ & \\
ATB2 & $0.859^{* *}$ & 0.804 \\
ATB3 & $0.848^{* *}$ & \\
Purchase intentions & & \\
PI1 & $0.732^{* *}$ & \\
PI2 & $0.792^{* *}$ & \\
PI3 & $0.817^{*}$ & 0.835 \\
PI4 & $0.778^{* *}$ & \\
PI5 & $0.777^{* *}$ & \\
$* * p \leq 0.01$ &
\end{tabular}

A 2 (facial expression: smiling vs. resting) $\mathrm{X} 2$ (cognitive capacity: load vs. no load) two-way ANOVA design, and emotional contagion of participants as the response variable constructed to test hypothesis 1 . The result shows that the smile of endorser in an ad was capable of enhancing participants' feelings significantly in both the cognitive capacity of load and no load conditions $(F=$ $6.188, p=0.014)$.

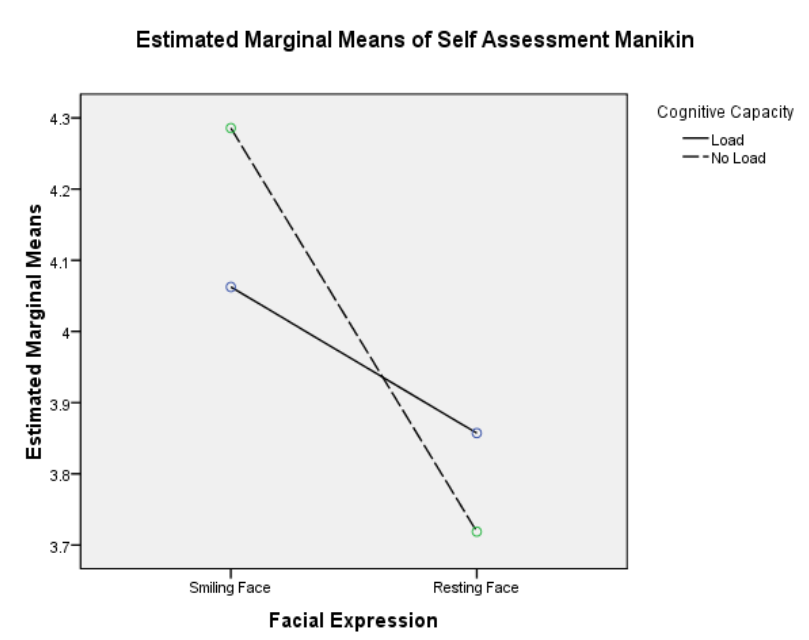

Figure 1. Emotion of participant on the manipulated condition

Referring to Figure 1, participants' feeling of happiness demonstrated by SAM would increase significantly during the smiley face expression of the endorser, regardless of the perceived cognitive capacity condition. Thus, hypothesis 1 was supported by empirical data.

Based on the summary of Regression analysis result in Table 2, it can be seen that hypothesis 2 was supported by empirical data. In hypothesis $2 \mathrm{a}$, the direct influence of facial expressions on attitude towards advertising was significant $(\beta=0.230, p=$ 0.012). Nevertheless, the magnitude of the effect was decreased and still significant $(\beta=0.142, p=$
0.097) when involving the role of SAM as a mediator $(\beta=0.395, p=0.000)$ in attitude towards advertising. Taking into account that the direct influence of facial expression on SAM was also significant $(\beta$ $=0.223, p=0.015)$, the condition in hypothesis $2 \mathrm{a}$ shows that SAM partially mediates the effect of facial expression on attitude towards advertising.

Table 2. The summary of Regression analysis result

\begin{tabular}{|c|c|c|c|c|}
\hline \multicolumn{2}{|c|}{ Variable's path } & $\begin{array}{l}\text { Standardized } \\
\text { estimate }(\beta)\end{array}$ & $p$ & Remark \\
\hline \multicolumn{5}{|l|}{ Hypothesis $2 \mathrm{a}$} \\
\hline $\mathrm{FE}^{\mathrm{a})} \rightarrow \mathrm{ATA}^{\mathrm{b})}$ & & 0.230 & 0.012 & \multirow{4}{*}{$\begin{array}{l}\mathrm{H} 2 \mathrm{a} \\
\text { supported }\end{array}$} \\
\hline $\mathrm{FE} \rightarrow \mathrm{SAM}^{\mathrm{c})}$ & & 0.223 & 0.015 & \\
\hline $\mathrm{FE}$ & FE & 0.142 & 0.097 & \\
\hline $\mathrm{SAM} \rightarrow \mathrm{ATA}$ & SAM & 0.395 & 0.000 & \\
\hline \multicolumn{5}{|l|}{ Hypothesis $2 b$} \\
\hline $\mathrm{FE} \rightarrow \mathrm{ATB}^{\mathrm{d})}$ & & 0.121 & 0.189 & \multirow{4}{*}{$\begin{array}{l}\mathrm{H} 2 \mathrm{~b} \\
\text { supported }\end{array}$} \\
\hline $\mathrm{FE} \rightarrow \mathrm{SAM}$ & & 0.223 & 0.015 & \\
\hline $\mathrm{FE}$ & $\mathrm{FE}$ & 0.070 & 0.444 & \\
\hline $\mathrm{SAM} \rightarrow \mathrm{ATB}$ & SAM & 0.226 & 0.015 & \\
\hline \multicolumn{5}{|l|}{ Hypothesis 2c } \\
\hline $\mathrm{FE} \rightarrow \mathrm{PI}^{\mathrm{e})}$ & & 0.124 & 0.177 & \multirow{4}{*}{$\begin{array}{l}\mathrm{H} 2 \mathrm{c} \\
\text { supported }\end{array}$} \\
\hline $\mathrm{FE} \rightarrow \mathrm{SAM}$ & & 0.223 & 0.015 & \\
\hline \multirow{2}{*}{$\mathrm{FE}, \mathrm{SAM} \rightarrow \mathrm{PI}$} & $\mathrm{FE}$ & 0.073 & 0.429 & \\
\hline & SAM & 0.230 & 0.014 & \\
\hline
\end{tabular}

${ }^{a)}$ Facial expression, ${ }^{\text {b) }}$ Attitude toward advertising, ${ }^{\text {c) }}$ Selfassessment manikin, ${ }^{\mathrm{d})}$ Attitude toward brand, ${ }^{\mathrm{e}}$ Purchase intentions

In hypothesis $2 \mathrm{~b}$, the direct influence of facial expressions on attitude towards brand was not significant $(\beta=0.121, p=0.189)$. Nevertheless, the effect of facial expressions on SAM was significant $(\beta=$ $0.223, p=0.015)$, and the effect of SAM on attitude towards brand was also significant $(\beta=0.226, p=$ $0.015)$. It signifies that SAM fully mediates the influence of facial expressions on attitude towards brand.

The analysis of mediation correlation on hypothesis $2 \mathrm{c}$ was not much different from hypothesis $2 \mathrm{~b}$. The direct effect of facial expressions on purchase intentions was not significant $(\beta=0.124, p=0.177)$, but the effect on SAM was significant $(\beta=0.223, p$ $=0.015)$. Taking into consideration that the effect of SAM is also significant on purchasing intentions $(\beta$ $=0.230, p=0.014$ ), then SAM fully mediates the influence of facial expression on purchase intentions.

\section{CONCLUSIONS}

Through a series of analyzes discussed in the previous section, a smile is very meaningful for consumer evaluation. Consumers will feel happier when the endorser's smiley face expression compared with a 
flat facial expression. Furthermore, the positive emotion in the form of pleasure feeling will mediate the effect of a smile on the consumer's evaluation. Consumer evaluation in this study is limited to attitudes toward advertising, brands, and purchase intentions.

The results of this study are in line with the results of previous studies, who argue that a smile contains a psychological message that can enhance the positive emotions of others. Further research needs to accommodate other variables that supposedly also play a role in facial expression relationships with consumer evaluations, such as the familiarity of the endorser, and the level of consumer involvement with the advertised product.

\section{REFERENCES}

Baron, R.M. \& Kenny, D.A. 1986. The moderator-mediator variable distinction in social psychological research: Conceptual, strategic, and statistical considerations. Journal of Personality \& Social Psychology 51(6): 1173-1182.

Baxter, S., Kulczynski, A. \& Ilicic, J. 2014. Revisiting the automaticity of phonetic symbolism effects. International Journal of Research in Marketing 31(4): 448-451.

Bradley, M.M. \& Lang, P.J. 1994. Measuring emotion: The self-assessment manikin and the semantic differential. Journal of Behavior Therapy and Experimental Psychiatry 25(1): 49-59.

Choi, S.M. \& Rifon, N.J. 2012. It is a match: The impact of congruence between celebrity image and consumer ideal self on endorsement effectiveness. Psychology \& Marketing 29(9): 639-650.

Davis, D.F. \& Herr, P.M. 2014. From bye to buy: Homophones as a phonological route to priming. Journal of Consumer Research 40(6): 1063-1077.

Doherty, R.W. 1997. The emotional contagion scale: A measure of individual differences. Journal of Nonverbal Behavior 21(2): 131-154.

Fitzsimons, G.J., Hutchinson, J.W., Williams, P., Alba, J.W., Chartrand, T.L., Huber, J. 2002. Non-conscious influences on consumer choice. Marketing Letters 13(3): 269-279.

Hair Jr, J.F., Black, W.C., Babin, B.J. \& Anderson, R.E. 2010. Multivariate data analysis. Englewood Cliffs: PrenticeHall.

Ilicic, J. \& Webster, C.M. 2011. Effects of multiple endorsements and consumer-celebrity attachment on attitude and purchase intention. Australasian Marketing Journal 19(4): 230-237.

Kulczynski, A., Ilicic, J. \& Baxter, S.M. 2016. When your source is smiling, consumers may automatically smile with you: Investigating the source expressive display hypothesis. Psychology \& Marketing 33(1): 5-19.

MacKinnon, D.P., Lockwood, C.M., Hoffman, J.M., West, S.G. \& Sheets, V. 2002. A comparison of methods to test mediation and other intervening variable effects. Psychological Methods 7(1): 83-104.

Sekaran, U. \& Bougie, R. 2016. Research methods for business: A skill building approach. Chichester: John Wiley \& Sons Ltd.

Soussignan, R. 2002. Duchene smile, emotional experience, and autonomic reactivity: A test of the facial feedback hypothesis. Emotion 2(1): 52-74.
Winkielman, P., Berridge, K.C. \& Wilbarger, J.L. 2005. Unconscious affective reactions to masked happy versus angry faces influence consumption behavior and judgments of value. Personality and Social Psychology Bulletin 31(1): 121-135.

Yoo, C. \& MacInnis, D. 2005. The brand attitude formation process of emotional and informational ads. Journal of Business Research 58(10): 1397-1406.

Zikmund, W.G., Babin, B.J., Carr, J.C. \& Griffin, M. 2013. Business research methods. New York: McGraw-Hill. 